Robert A. Gross, MD, PhD, FAAN

Editor-in-Chief, Neurology ${ }^{\circledR}$

Treatment of chronic tinnitus with theta burst stimulation: A randomized controlled trial $\underline{\underline{\underline{ }}}$

Forty-eight patients with chronic tinnitus received 4 weeks (20 sessions) of bilateral continuous theta burst stimulation.

Treatments to the temporal or temporoparietal cortex of both hemispheres appear safe but not more effective than sham stimulation.

See p. 1628; Editorial, p. 1624

$\mathrm{Na}_{\mathrm{v}}$ 1.7-related small fiber neuropathy: Impaired slowinactivation and DRG neuron hyperexcitability :-

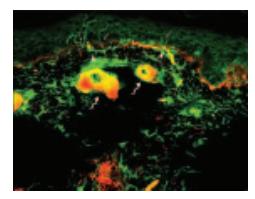

A patient with small fiber neuropathy (SFN) symptoms was evaluated by skin biopsy, quantitative sensory testing, nerve conduction studies, screening of genomic DNA for variants in SCN9A, and functional assessment. The findings suggest that variants of $\mathrm{Na}_{\mathrm{v}} 1.7$ may impair slow-inactivation, producing dorsal root ganglion neuron hyperexcitability contributing to pain in SFN. See p. 1635

From editorialist Stephen C. Cannon: "The question implied by the title of this editorial is to convey the remaining uncertainty for the causal association of $\mathrm{Na}_{v} 1.7$ sequence variants with SFN and for the clinical application of these findings."

See p. 1626

Placebo-controlled trial of lubiprostone for constipation associated with Parkinson disease $\mathbb{E}$ 를

Constipation is a major complaint in Parkinson disease and may interfere with levodopa absorption. Fifty-four patients with Parkinson disease and clinically meaningful constipation were randomized to lubiprostone or placebo. Lubiprostone, up to $24 \mu \mathrm{g}$ twice daily, markedly improved constipation and was generally well tolerated.

See p. 1650

Diffusion-weighted imaging characteristics of biopsy-proven demyelinating brain lesions

Forty prebiopsy apparent diffusion coefficient (ADC) maps were reviewed from 30 patients with CNS inflammatory demyelinating disease. Lesions were analyzed for size, T2W hypointense rim, enhancement, and ADC pattern.

Characteristic features on ADC maps may help diagnose demyelinating disease and obviate the need for biopsy.

See p. 1655
COMT Val ${ }^{158}$ Met genotype influences neurodegeneration within dopamine-innervated brain structures

Using voxel-based morphometry, the authors found that patients with neurodegenerative disease carrying the $\mathrm{Val}^{158} \mathrm{Met}$ allele of the catechol-O-methyltransferase gene had reduced gray matter in dopamine-innervated brain structures. The results are consistent with the hypothesis that increased synaptic dopamine catabolism promotes neurodegeneration within dopamine-innervated brain regions.

See p. 1663

Inpatient statin use predicts improved ischemic stroke discharge disposition

The authors used generalized ordinal logistic regression to analyze discharge disposition among 12,689 patients with ischemic stroke over a 7-year period. Statin therapy should be considered to reduce the chance of a future stroke and, furthermore, as an in-hospital intervention to improve poststroke outcomes.

See p. 1678

\section{Comparative safety of antiepileptic drugs during pregnancy} This paper considers the safety of anticonvulsants for women with epilepsy of childbearing age. Antiepileptic drugs (valproate and phenobarbital) were associated with a higher risk of malformations than newer drugs (lamotrigine and levetiracetam). While the lower risk associated with newer drugs is reassuring, the increased risk of clefts in newborns exposed to topiramate has raised concern. See p. 1692

NB: “Developmental prosopagnosia in a patient with hypoplasia of the vermis cerebelli," see p. 1700. To check out other Clinical/ Scientific Notes, point your browser to www.neurology.org.

Podcasts can be accessed at www.neurology.org 


\section{Neurology}

Spotlight on the May 22 Issue

Robert A. Gross

Neurology 2012;78;1623

DOI 10.1212/WNL.0b013e3182574fb8

\section{This information is current as of May 21, 2012}

\section{Updated Information \&} Services

Permissions \& Licensing

Reprints including high resolution figures, can be found at: http://n.neurology.org/content/78/21/1623.full

Information about reproducing this article in parts (figures,tables) or in its entirety can be found online at:

http://www.neurology.org/about/about_the_journal\#permissions

Information about ordering reprints can be found online:

http://n.neurology.org/subscribers/advertise

Neurology ${ }^{\circledR}$ is the official journal of the American Academy of Neurology. Published continuously since 1951, it is now a weekly with 48 issues per year. Copyright Copyright $@ 2012$ by AAN Enterprises, Inc.. All rights reserved. Print ISSN: 0028-3878. Online ISSN: 1526-632X.

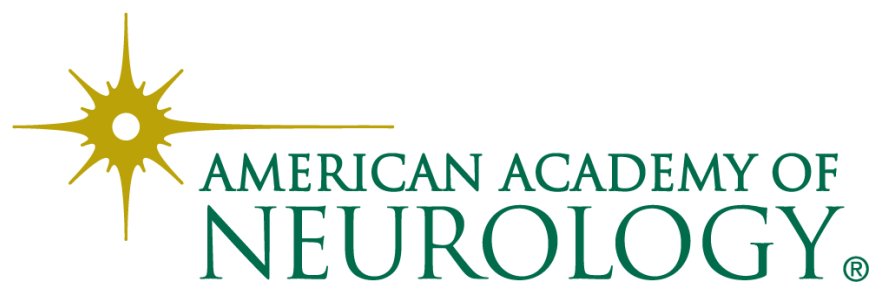

